\title{
Genetic and medical advising information and education tools for the patient and his family
}

\begin{abstract}
Summary
Communication between doctor and patient, while medical attention process, is a priceless tool to achieve a good outcome, as well as the fulfillment of the expectations of the patient and his family. Effective communication between the doctor and his patient: increases diagnostic accuracy, the patient's adherence to treatment and it builds a mutual support net between the doctor and his patient. The relation between communication and treatment adherence is not simple, there are many systematic revisions in which it has been possible to evidence that the high levels of treatment adherence are associated with communication models that they take in consideration, attitudes, beliefs, and patients preferences allowing a negotiation process with a higher agreement and comprehension. The current orientation of medical care towards meeting the needs of users of medical services (medical care quality), make it necessary to consider two closely linked dimensions: The application of science to solve a problem (scientific-technical quality) and the satisfaction of the user and his family regarding the care process provided (perceived quality). The incorporation of a procedure that beyond to be an informative activity, acquires a structure of medical advice, entails the reorientation not only of the hospital care systems; if not, also the incorporation of complementary subjects in the academic programs that instruct the doctors in training for a more inclusive model of care for the patient, in which the main tool is the medical advice procedure. With the aim of carrying out a detailed review of the elements used in the structuring of the genetic counseling process and transferring them as a methodological model guide for the integration (structuring) of a medical advice process that allows improving information and education processes for the patient and his family, we carry out a bibliographical review and offer the reader the following considerations.
\end{abstract}

Keywords: information, achievement, education, incorporation, genetic counseling, bibliographical review, perceived quality, dimensions, family
Volume 2 Issue 4 - 2018

\author{
Olvera-Sumano Verónica,' Jiménez-Ríos \\ Patricia, ${ }^{2}$ Reyes-Olvera Valeria Justine, ${ }^{3}$ \\ Azamar-Cruz Erick ${ }^{4}$ \\ 'Departamento de Genética, Hospital Regional de Alta \\ Especialidad de Oaxaca, Mexico \\ ${ }^{2}$ Servicio de Anestesiología, Hospital Regional de Alta \\ Especialidad de Oaxaca, Mexico \\ ${ }^{3}$ Facultad de Medicina, Universidad Regional del Sureste, Mexico \\ ${ }^{4}$ Dirección de Planeación, Enseñanza e Investigación, Hospital \\ Regional de Alta Especialidad de Oaxaca, Mexico
}

Correspondence: Olvera Sumano Verónica, Departamento de Genética, Hospital Regional de Alta Especialidad de Oaxaca, Mexico, Email verónica_o_s@hotmail.com

Received: June 06, 2018 | Published: July 06, 2018

\section{Introduction}

One of the manly missions of the healthcare professionals is to communicate the consultant in a clear and comprensible way the known facts in relation to his illness, so he can have the capacity to take his own decisions in a informed and conscious way. This information process, keeps an incalculable value for the doctor-patient relation, whose clinical sustenance, ethical, legal and deontological has been varying in relevance according to the cultural changes of society. Adapting little by little as a daily activity of the clinical work, as it is the diagnostic or treatment process; nevertheless it is considered "sub evaluated" since this information process, represents an important tool for the patients recovery, or a tracer element to evaluate the quality of the medical attention ${ }^{1,2}$ it has also been related with a better diagnostic integration, less incidence of bad practice judgments, better treatment adherence, greater patient satisfaction and a better outcome. This process has been structured in a more formal and scientific way in the practice of the medical genetics also known as clinical genetics, under the concept of genetic counseling; understood as a bidirectional communication process not directed, that the doctor keeps with a person in relation to his ailment, evolution or transmission of one genetic origin disease, therefore, we consider it appropriate to conduct a review of this structuring for later compare it with the daily information process that every doctor performs in relation to common diseases, with the goal to put forward a better structured process, both for the patient and for his treating doctor, that would be reflected in the improvement of communication channels so necessary between the doctor and patient, as well as between the doctor and the family or group of caregivers of the patient, as a key axis of a better care process.

\section{General purpose}

Characterize the elements used in the structuring of the genetic counseling process and transfer them as a methodological model guide for the integration (structuring) of a medical counseling process that allows improving the information and education processes for the patient and their family.

Methodology: Bibliographic review.

\section{Information process (communication) doctor-patient}

Giving information to the patients and familiars is an indispensable procedure inside heals care process; determining factor in meeting the needs and it is a primordial right for the patient. The success of any clinical interview depends on the quality of the communication between the doctor and his patient. Effective communication skills, are part of the task of a good doctor and therefore, communication should be considered one of the basic skills in the medical formation. ${ }^{3,4}$ Effective communication between the doctor and his patient: increases diagnostic accuracy, the patients adherence to treatment and it builds 
a mutual support net between the doctor and his patient. The relation between communication and treatment adherence is not simple, there are many systematic revisions in which it has been possible to evidence that the high levels of treatment adherence are associated with communication models that they take in consideration, attitudes, beliefs, and patients preferences allowing a negotiation process with a higher agreement and comprehension. Using an effective communication by the doctors as part of their attention process benefits both the professionals and the patients. One side, the doctor identify the patient problems with higher precision and in the other side lawsuits and litigations against them diminish, ${ }^{5-8}$ satisfaction level of both increase, ${ }^{9}$ allowing even decrease in the doctor the incidence of Burn-out syndrome. ${ }^{10,11}$ In this context, Kurtz describes effective communication, as the communication process based on the following principles ${ }^{12}$

i. Ensure an interaction, instead a direct transmission (there are opportunities to interchange questions and answers).

ii. Reduce unnecessary uncertainty, using a clear language for the patient and in a concrete way about his prognostic and treatment plan.

iii. Make a plan: it is important in this aspect for the doctor to plan, basing on the patient's intercultural background (collected in the clinical history) to improve the quality of communication,

iv. Show dynamism: it implicates the good reaction of the doctor in front of the behavior shown by the patient, what implicates flexibility and many abilities for the doctor.

v. It follows a helical process more than a lineal one: it implicates explaining the patient one and again about his ailment and treatment, gradually raising the level of information, but with the flexibility to go back to basic information if necessary.

Nevertheless, the truth is that the current attention process that is managed at the level of health institutions in Mexico, limits the information process due to the overload of consultation and the limited time that is allocated for the care of each patient; in addition to the great lack that exists in the curricula, of subjects that guide the preparation of medical students to perform this task, which directly affects in the quality of care perceived by the patient, translating into low percentages of satisfaction and increase in the number of demands made to doctors for probable mal praxis. On the other hand genetic achievement, also known as genetic counseling, is a structured communication process established with the patient, about the human problems associated with the occurrence, or risk of the occurrence of a familial genetic disorder. The purpose of this communication process is to help the individual, or the family, to face the different situations that arise and are related to the illness for which they consult. Due to the complexity that the person problem may have, genetic counseling should include enough information; in such a way that who receives it would be able to:

i. To understand medical aspects, this includes the diagnosis, probable curse of the disease and the management options with their respective implications. A very important part is to make the patient learn the name of their condition and their homologous or alternative names if that is the case.

ii. To understand the way in which inheritance contributes to produce the disease and the risk of repetition or recurrence of this. iii. Guide the patient by providing the necessary information and in terms understandable to him regarding the different management options available, in order to allow him to choose freely the course of action (treatment option) that the patient considers most appropriate due to the risk, family goals, ethical in accordance with this decision.

iv. Make the best possible adjustment to the pathology in an affected member of the family and/or the risk of repetition of this disorder.

The person requesting genetic counseling (GC) may be affected by the disease (propositus) or be a seemingly healthy family member of the affected (consultant). Genetic counseling is born from the need to help individuals and families with a diagnosis or risk of a hereditary genetic condition, to understand and adapt to the implications to which the results of genetic studies often entail. As part of the health care team, genetic counselors provide information and assistance not only to patients; if not also to families affected by a genetic disorder or at risk of presenting one. They also function as a central resource for information on genetic disorders for other medical professionals, for patients and for the general public. ${ }^{13}$ A genetic counselor collects and analyzes family history and hereditary patterns in order to calculate the probability of recurrence of a genetic disorder in the offspring of the patient (propositus); as well as in their relatives and the descendants of them; for this purpose, they receive training during their well-established training process, which aims to promote the ability to present the patient with complex information on genetic risks, tests and diagnoses in a clear and understandable manner for the patient and their family. Because in this process there is a significant emotional burden, the counselor should be a qualified staff, aware of their limitations, empathic and have a great ability to communicate, through both verbal and non-verbal language; as well as behave with strict adherence to the ethical principles of autonomy, confidentiality, non-directive counseling, promotion of reproductive autonomy and equity in accessing the benefits of the GA, ${ }^{14}$ in the same way, having enough training to be able to select an appropriate communication strategy with the religious and ethical beliefs of the patient and his family (from his own worldview), which allows transmitting the information with the least psychological impact for the patient and his family. Genetic counseling includes a series of processes that must be done in an established order.

\section{Make the correct diagnosis}

The realization of a correct diagnosis must be based on an adequate clinical history, the family history should be detailed, including the graphic representation of the family tree; and the presence of one or more affected relatives will allow to know the possible hereditary pattern of the disease. On the other hand, the physical examination of the patient must be complete and detailed, including anthropometric measurements and photographs if necessary. Complementary studies will almost always be necessary to confirm or rule out a clinical suspicion based on the anamnesis and physical examination. However, it should be considered that from 40 to $50 \%$ of the cases studied it is not possible to obtain a specific genetic diagnosis, however, the fact of keeping the patient informed about the researches carried out, greatly decreases their anxiety and contributes to form an environment of mutual collaboration between the doctor and his patient.

\section{Calculate the risk of recurrence}

Having the certainty of the hereditary model that presents a disease or genetic pathology allows to offer a reliable genetic counseling, 
with a precise quantification of the risk of recurrence; in the case of pathologies with well-known hereditary models and of classical transmission or for those suffering from non-classical transmission. However, in the case of cytogenetic, sporadic or multifactorial pathologies; there are different methodologies for estimating these risks, for example empirical risk, whose estimation is usually based on epidemiological studies carried out in different populations. ${ }^{15}$

\section{Transmit the information to the patient and/or the family}

It is carried out after a strategic planning in which diverse ethnic, cultural, social, religious, personal and family backgrounds are taken into account, which include psychological aspects of the patient and his family, that is, the analysis of its determinants. This process is one of the most important within the structure that represents genetic counseling.

\section{Review available options}

In this aspect it is very important to provide the patient with information regarding the multidisciplinary team responsible for its management and to allow it to be in charge of making the best decision regarding its care.

\section{Plan the follow-up of the process}

Taking into account that these are chronic diseases that warrant follow-up and / or multidisciplinary interventions, it is important to trace to the patient a follow-up plan of their pathology in the short, medium and long term. ${ }^{16}$ There are some indications for which genetic counseling is requested, including a previous or family child with one or more congenital malformations, a previous or family child with mental retardation, a previous child or family member affected by a known genetic disease, a family history of cancer, a fetus with malformations or pregnancy with abnormal prenatal markers, repeat or infertility abortions, consanguinity, exposure of pregnant to possible teratogen, etc. Traditionally, AG is generally provided worldwide by geneticists or doctors with advanced knowledge in genetics. However, due to the diversification of the reasons for which genetic counseling is sought and recent advances in the diagnosis of pathologies with a partial genetic component, this information process has been extended to different disciplines that are not predominantly managed by the geneticist. ${ }^{17}$ Advances in the knowledge of genetics have created the need to provide genetic counseling in all areas of primary health care and in various specialties such as oncology and cardiology, which has opened the possibility that genetic counseling is provided in the future by doctors or other health personnel prepared specifically for this purpose. ${ }^{18}$

\section{Why transform the medical report into a medical advice process?}

The current orientation of medical care towards satisfying the needs of users of medical services (quality of medical care), makes it necessary to consider two closely linked dimensions: the application of science for the resolution of a problem (scientific quality) -technical) and the satisfaction of the user and family members regarding the care process provided (perceived quality). It is estimated that a doctor performs between 86,000 and 120,000 interviews during his professional career, assuming that he attends between 3 and 4 patients per hour in a 22-hour day over 30 years. Only for this number of interviews it is valuable to pay attention to what can be done to make these interactions more satisfactory. It is important to consider what is achieved when communication between patients and their doctors is effective. ${ }^{19}$ Having trained doctors not only to carry out an effective communication process with the patient, but also to act as true medical advisors, implies a double responsibility, both for the doctor and for the patient. For the physician implies the responsibility of providing structured, clear and truthful information to the patient regarding his pathological process, the factors that trigger and aggravate it, the different treatment options and the recurrence risks for him and his family taking into account the intercultural background of each patient and in strict adherence to established ethical principles. And for the patient, it implies taking responsibility in making informed decisions and with full knowledge of the risks and benefits that these decisions entail in their care process; as well as the direct implications that they can have on the evolution and outcome of their pathological process, probably translating into greater adherence to treatment and better decisions on the part of the patient. In this way, the information, as well as the feedback provided by the patient, can be better structured and documented in the clinical file, providing greater certainty for the doctor and greater responsibility for the patient, who is directly involved and included in the process of attention.

\section{Conclusion}

The high standards of demand regarding quality in medical care, makes it necessary to restructure the process of training health personnel, with emphasis on medical personnel. It is necessary to provide medical students with the necessary tools to establish channels of direct communication with patients and their families; as well as establishing a universal methodology that is flexible enough to be adapted to diverse medical situations and in which it is necessary the doctor's knowledge of the cultural, religious and social factors within the patient's ideology (interculturality) that could influence in the form of understanding of the patient regarding his pathological process and therefore in making decisions regarding his treatment and reproductive future. These changes not only involve modifying the academic programs in which a subject of medical advice is included; but to modify in itself the process of attention, in which an exclusive space is destined to the communication of the doctor with his patient, under the scheme of medical advice; as it currently exists under the modality of genetic counseling, including within this process the signing of the patient's prior consent (letter of informed consent) to receive such information. In another order of ideas, the implementation of a medical advisory program in the hospital units, should include a model for evaluating the effectiveness of the advice that allows the continuous improvement of the same, for the benefit of the population served, which represents a task of great clinical medical value.

\section{Acknowledgements}

None.

\section{Conflict of interest}

The author declares there is no conflict of interest.

\section{References}

1. Rosselot E. Derechos del paciente, en el marco de la calidad de la atenci"'on médica. Rev Med Chile. 2000;128:904-910.

2. P Moore. La comunicación médico-paciente ¡cuáles son las habilidades efectivas? Rev Med Chile. 2010;138:1047-1054. 
3. Moore P, Gómez G. Comunicarse efectivamente en Medicina ¿Cómo adquirir Habilidades Comunicacionales durante la carrera de Medicina? Ars Medica. 2012;44(6):358-365.

4. Association of American Medical Colleges. Medical School Objectives Project: Report III -Contemporary Issues in Medicine: Communication in Medicine. Association of American Medical Colleges; 1999.

5. Stewarrt MA. Effective physician-patient communication and health outcomes: a review. CMAJ. 1995;152(9):1423-1433.

6. Haynes RB, Ackloo E, Sahota N, et al. Interventions for enhansing medication adherence. Cochrane Database Syst Rev. 2008;16(2): CD000011.

7. Coambs RB. Review of Scientific Literature on prevalence, Consequences and Health Costs of Noncompliance and Inappropiate use of prescription medication in Canada. University of Toronto Press; 1995.

8. Tamblyn R, Abrahamowics M, Dauphinee D, et al. Physician scores on a national clinical skins examination as predictors of complaints to medical regulatory authorities. JAMA. 2007;298(9):993-1001.

9. Lewin SA, Skea ZC, Entwistle V, et al. Interventins for providers to promote a patient-centred approach in clinical consultations. Cochrane Database Sysr Rev. 2001;(4):CD003267.

10. Cebria J, Palma C, Segura J, et al. El entrenamiento en habilidades de comunicación podría ser un factor predictivo del síndrome de burnout en médicos de familia. Rev Psiquiatría Fac Med Barna. 2006;33(1):34-40.
11. Epstein RM. Communication, burnout and clinical results: more questions tan answers. Aten Primaria. 2001;27(7):511-513.

12. Silverman J, Kurtz S, Draper J. Skills for communicating with patients $2^{\text {nd }}$ edition. Radcliffe Medical Press. 2005;88(1):85-86.

13. D Pinto-Escalante, JM Ceballos-Quintal, I Castillo-Zapata. Fundamentos y actualidades del asesoramiento genético. Rev Biomed. 2001;12:186-195.

14. Lisker R, Carnevale A, Armendares S. Mexican geneticists' views of ethical issues in genetics testing and screening. Are eugenic principles involved? Clin Genet. 1999;56:323-327.

15. Young ID. Introduction to risk calculation in genetic counseling. 3rd edition. New York: Oxford University Press, Inc. 2007.

16. Fernanda CG, Polubriaginof, Rami Vanguri, et al. Disease Heritability Inferred from Familial Relationships Reported in Medical Records. Cell. 2018;173(7):692-1704.

17. Delphine Blain MS, Brian P, Brooks. Molecular Diagnosis and Genetic Counseling in Ophthalmology. Arch Ophthalmol. 2007; 125(2):196-203.

18. Allison W, Kurian MD, Kent A, et al. Genetic Testing and Counseling Among Patients With Newly Diagnosed Breast Cancer. JAMA. 2017;317(5):531-534.

19. Stewart MA. Effective physician-patient communicationand health outcomes: a review. CMAJ. 1995;152:1423-1433. 